Supporting information

\title{
The Modular Synthesis of Functional Porous Coordination Networks
}

Masaki Kawano,* Takehide Kawamichi, Tsuyoshi Haneda, Takahiro Kojima, and Makoto Fujita*

\section{Contents}

Experimental Details

Crystallographic Data for 3b-3f, 4a-4c.

Figure S1-S15. Crystal Structure and ORTEP drawing for 3b-3f.

Figure S16-S18. Crystal Structure and ORTEP drawing for 4a-4c.

Figure S19-S21. TGA curve for 4a-4c. 


\section{Experimental Details}

General Method: Reagents and solvents were obtained from commercial suppliers and used without further purification.

Typical Procedure of guest exchange: The crystals of 3a-3c (25 mg) were immersed in a propane-2-ol/cyclohexane solution (1:39, $1 \mathrm{ml})$. After 2 days, the crystals were removed from the solution and the X-ray analyses were revealed the inclusion complexes (4a-4c). The crystallographic details were described in the cif files.

\section{Elemental analysis:}

Anal Calcd for $\mathrm{C}_{78} \mathrm{H}_{58} \mathrm{I}_{6} \mathrm{~N}_{16} \mathrm{O}_{10} \mathrm{Zn}_{3}\left\{\left[\left(\mathrm{ZnI}_{2}\right)_{3}(\mathbf{1})_{2}(\mathbf{2 b})\right] \cdot 4\left(\mathrm{C}_{6} \mathrm{H}_{5} \mathrm{NO}_{2}\right) \cdot\left(\mathrm{H}_{2} \mathrm{O}\right)\right\}(3 \mathbf{b}): \mathrm{C}, 40.09 ; \mathrm{H}$, 2.50; N, 9.59. Found C, 40.22; H, 2.50; N, 9.59.

Anal Calcd for $\mathrm{C}_{79} \mathrm{H}_{60} \mathrm{I}_{6} \mathrm{~N}_{16} \mathrm{O}_{10} \mathrm{Zn}_{3}\left\{\left[\left(\mathrm{ZnI}_{2}\right)_{3}(\mathbf{1})_{2}(2 \mathrm{c})\right] \bullet 4\left(\mathrm{C}_{6} \mathrm{H}_{5} \mathrm{NO}_{2}\right) \cdot(\mathrm{MeOH})\right\}(3 \mathrm{c}): \mathrm{C}, 40.35 ; \mathrm{H}$, 2.58; N, 9.53. Found C, 40.60; H, 2.70; N, 9.32.

Anal Calcd for $\mathrm{C}_{78} \mathrm{H}_{57} \mathrm{I}_{6} \mathrm{~N}_{17} \mathrm{O}_{8} \mathrm{Zn}_{3}\left\{\left[\left(\mathrm{ZnI}_{2}\right)_{3}(\mathbf{1})_{2}(\mathbf{2 d})\right] \bullet 4\left(\mathrm{C}_{6} \mathrm{H}_{5} \mathrm{NO}_{2}\right)\right\}(3 \mathbf{d}): \mathrm{C}, 40.42 ; \mathrm{H}, 2.48 ; \mathrm{N}$, 10.27. Found C, 40.47; H, 2.74; N, 9.98.

Anal Calcd for $\mathrm{C}_{78} \mathrm{H}_{57} \mathrm{I}_{6} \mathrm{~N}_{17} \mathrm{O}_{8} \mathrm{Zn}_{3}\left\{\left[\left(\mathrm{ZnI}_{2}\right)_{3}(\mathbf{1})_{2}(2 \mathbf{e})\right] \bullet 4\left(\mathrm{C}_{6} \mathrm{H}_{5} \mathrm{NO}_{2}\right)\right\}(3 \mathbf{e})$ : C, 40.42; H, 2.48; N, 10.27. Found C, 40.34; H, 2.68; N, 10.10.

Anal Calcd for $\mathrm{C}_{78} \mathrm{H}_{55} \mathrm{I}_{6} \mathrm{~N}_{17} \mathrm{O}_{10} \mathrm{Zn}_{3}\left\{\left[\left(\mathrm{ZnI}_{2}\right)_{3}(\mathbf{1})_{2}(2 \mathrm{f})\right] \cdot 4\left(\mathrm{C}_{6} \mathrm{H}_{5} \mathrm{NO}_{2}\right)\right\}(3 f): \mathrm{C}, 39.90 ; \mathrm{H}, 2.36$; N, 10.14. Found C, 40.12; H, 2.43; N, 10.19.

Anal Calcd for $\mathrm{C}_{66} \mathrm{H}_{53} \mathrm{I}_{6} \mathrm{~N}_{13} \mathrm{O}_{2} \mathrm{Zn}_{3}\left\{\left[\left(\mathrm{ZnI}_{2}\right)_{3}(\mathbf{1})_{2}(\mathbf{2 a})\right] \cdot(\right.$ Cyclohexane) $($ Nitrobenzene) $\}(4 \mathbf{a})$ : C, 39.29; H, 2.65; N, 9.02. Found C, 39.26; H, 2.89; N, 8.68.

Anal Calcd for $\mathrm{C}_{66} \mathrm{H}_{62} \mathrm{I}_{6} \mathrm{~N}_{12} \mathrm{O}_{4} \mathrm{Zn}_{3}\left\{\left[\left(\mathrm{ZnI}_{2}\right)_{3}(\mathbf{1})_{2}(\mathbf{2 b})\right] \cdot 1.5(i-\mathrm{PrOH}) \cdot(\right.$ Cyclohexane $\left.) \cdot\left(\mathrm{H}_{2} \mathrm{O}\right)\right\}(\mathbf{4 b})$ : C, 38.37; H, 3.10; N, 8.33. Found C, 38.62; H, 3.11; N, 8.17.

Anal Calcd for $\mathrm{C}_{63} \mathrm{H}_{58} \mathrm{I}_{6} \mathrm{~N}_{12} \mathrm{O}_{3} \mathrm{Zn}_{3}\left\{\left[\left(\mathrm{ZnI}_{2}\right)_{3}(\mathbf{1})_{2}(\mathbf{2 c})\right] \cdot(i-\mathrm{PrOH}) \bullet(\right.$ Cyclohexane $\left.) \cdot\left(\mathrm{H}_{2} \mathrm{O}\right)\right\}(\mathbf{4 c})$ : C, 38.05; H, 2.94; N, 8.45. Found C, 37.99; H, 3.04; N, 8.23. 


\section{Crystallographic Data:}

3b: synchrotron radiation ( $\lambda=0.6890 \AA$ ) was used at PF-AR (NW2 beamline) of the High Energy Accelerator Research Organization (KEK). Data were collected on RIGAKU/MSC Mercury CCD X-ray diffractometer. The structures were solved by direct methods (SHELXS 97) and refined by full-matrix least-squares calculations on $F^{2}$ (SHELXL-97) using the SHELX-TL program package. Hydrogen atoms were fixed at calculated positions and refined using a riding model. $\mathrm{C}_{78.39} \mathrm{H}_{56} \mathrm{I}_{6} \mathrm{~N}_{16} \mathrm{O}_{10} \mathrm{Zn}_{3}, M r=2339.58$, crystal dimensions $0.15 \times$ $0.15 \times 0.10 \mathrm{~mm}^{3}$, Orthorhombic, space group, Pbca, $a=27.596(6), b=13.690(3), c=$ 45.419(9) $\AA, V=17158(6) \AA^{3}, T=80 \mathrm{~K}, Z=8, \rho$ calcd $=1.811 \mathrm{~g} \mathrm{~cm}^{-3}, 13705$ unique reflections out of 21121 with $I>2 \sigma(I), 1454$ parameters, $2.03<\theta<27.30^{\circ}$, final $R$ factors $R_{1}$ $=0.0529$ and $w R_{2}=0.1539$.

3c: the diffraction data were measured on a Bruker APEX/CCD diffractometer (MoK $\alpha$ radiation $\lambda=0.71073 \AA$ ) with a cryostat system equipped with a $\mathrm{N}_{2}$ generator (Japan Thermal Eng. Co., Ltd.). $\quad \mathrm{C}_{79} \mathrm{H}_{60} \mathrm{I}_{6} \mathrm{~N}_{16} \mathrm{O}_{10} \mathrm{Zn}_{3}, M r=2350.94$, crystal dimensions $0.45 \times 0.10 \times 0.05$ $\mathrm{mm}^{3}$, Orthorhombic, space group, Pbca, $a=27.123(4), b=13.682(2), c=45.995(6) \AA, V=$ 17068(4) $\AA^{3}, T=90 \mathrm{~K}, Z=8, \rho$ calcd $=1.830 \mathrm{~g} \mathrm{~cm}^{-3}, 16726$ unique reflections out of 24916 with $I>2 \sigma(I), 1117$ parameters, $1.72<\theta<30.08^{\circ}$, final $R$ factors $R_{1}=0.0382$ and $w R_{2}=$ 0.0867 .

3d: the diffraction data were measured on a Bruker APEX-II/CCD diffractometer equipped with a focusing mirror (MoK $\alpha$ radiation $\lambda=0.71073 \AA$ ) with a cryostat system equipped with a $\mathrm{N}_{2}$ generator (Japan Thermal Eng. Co., Ltd.). $\quad \mathrm{C}_{78} \mathrm{H}_{57} \mathrm{I}_{6} \mathrm{~N}_{17} \mathrm{O}_{8} \mathrm{Zn}_{3}, M r=2317.92$, crystal dimensions $0.20 \times 0.10 \times 0.10 \mathrm{~mm}^{3}$, Orthorhombic, space group, Pbca, $a=27.122(4), b=$ 13.692(2), $c=45.963(7) \AA, V=17069(5) \AA^{3}, T=80 \mathrm{~K}, Z=8, \rho$ calcd $=1.804 \mathrm{~g} \mathrm{~cm}^{-3}, 10773$ unique reflections out of 15041 with $I>2 \sigma(I), 1361$ parameters, $1.72<\theta<25.04^{\circ}$, final $R$ factors $R_{1}=0.0455$ and $w R_{2}=0.1077$.

3e: the diffraction data were measured on a Bruker APEX-II/CCD diffractometer equipped with a focusing mirror (MoK $\alpha$ radiation $\lambda=0.71073 \AA$ ) with a cryostat system equipped with a $\mathrm{N}_{2}$ generator (Japan Thermal Eng. Co., Ltd.). $\quad \mathrm{C}_{79.82} \mathrm{H}_{58.51} \mathrm{I}_{6} \mathrm{~N}_{17.30} \mathrm{O}_{8.59} \mathrm{Zn}_{3}, M r=2354.93$, crystal dimensions $0.20 \times 0.15 \times 0.10 \mathrm{~mm}^{3}$, Orthorhombic, space group, $P b c a, a=27.286(3)$, $b=13.670(2), c=45.829(6) \AA, V=17131(4) \AA^{3}, T=80 \mathrm{~K}, Z=8, \rho$ calcd $=1.826 \mathrm{~g} \mathrm{~cm}^{-3}$, 17876 unique reflections out of 21639 with $I>2 \sigma(I), 1682$ parameters, $1.72<\theta<28.90^{\circ}$, final $R$ factors $R_{1}=0.0709$ and $w R_{2}=0.1651$. 
3f: the diffraction data were measured on a Bruker APEX-II/CCD diffractometer equipped with a focusing mirror (MoK $\alpha$ radiation $\lambda=0.71073 \AA$ ) with a cryostat system equipped with a $\mathrm{N}_{2}$ generator (Japan Thermal Eng. Co., Ltd.). $\quad \mathrm{C}_{78} \mathrm{H}_{55} \mathrm{I}_{6} \mathrm{~N}_{17} \mathrm{O}_{10} \mathrm{Zn}_{3}, M r=2347.90$, crystal dimensions $0.20 \times 0.20 \times 0.10 \mathrm{~mm}^{3}$, Orthorhombic, space group, Pbca, $a=27.424(3), b=$ 13.793(1), $c=45.907(5) \AA, V=17365(3) \AA^{3}, T=80 \mathrm{~K}, Z=8, \rho$ calcd $=1.796 \mathrm{~g} \mathrm{~cm}^{-3}, 16275$ unique reflections out of 21992 with $I>2 \sigma(I), 1278$ parameters, $1.77<\theta<28.96^{\circ}$, final $R$ factors $R_{1}=0.0500$ and $w R_{2}=0.1444$.

4a: the diffraction data were measured on a Bruker APEX/CCD diffractometer (MoK $\alpha$ radiation $\lambda=0.71073 \AA$ ) with a cryostat system equipped with a $\mathrm{N}_{2}$ generator (Japan Thermal Eng. Co., Ltd.). $\quad \mathrm{C}_{79.20} \mathrm{H}_{79.40} \mathrm{I}_{6} \mathrm{~N}_{13} \mathrm{O}_{2} \mathrm{Zn}_{3}, M r=2202.87$, crystal dimensions $0.10 \times 0.10 \times$ $0.05 \mathrm{~mm}^{3}$, Orthorhombic, space group, Pbca, $a=27.881(6), b=13.675(3), c=45.714(9) \AA$, $V=17430(6) \AA^{3}, T=90 \mathrm{~K}, Z=8, \rho$ calcd $=1.679 \mathrm{~g} \mathrm{~cm}^{-3}, 17113$ unique reflections out of 22108 with $I>2 \sigma(I)$, 975 parameters, $1.71<\theta<28.99^{\circ}$, final $R$ factors $R_{1}=0.0480$ and $w R_{2}$ $=0.1228$.

4b: the diffraction data were measured on a Bruker APEX-II/CCD diffractometer equipped with a focusing mirror (MoK $\alpha$ radiation $\lambda=0.71073 \AA$ ) with a cryostat system equipped with a $\mathrm{N}_{2}$ generator (Japan Thermal Eng. Co., Ltd.). $\quad \mathrm{C}_{75} \mathrm{H}_{84} \mathrm{I}_{6} \mathrm{~N}_{12} \mathrm{O}_{5.07} \mathrm{Zn}_{3}, M r=2192.09$, crystal dimensions $0.30 \times 0.20 \times 0.15 \mathrm{~mm}^{3}$, Orthorhombic, space group, Pbca, $a=27.449(4), b=$ 13.707(2), $c=45.248(7) \AA, V=17024(5) \AA^{3}, T=82 \mathrm{~K}, Z=8, \rho$ calcd $=1.711 \mathrm{~g} \mathrm{~cm}^{-3}, 13293$ unique reflections out of 20938 with $I>2 \sigma(I), 1091$ parameters, $1.72<\theta<28.29^{\circ}$, final $R$ factors $R_{1}=0.0645$ and $w R_{2}=0.1811$.

4c: the diffraction data were measured on a Bruker APEX-II/CCD diffractometer equipped with a focusing mirror (MoK $\alpha$ radiation $\lambda=0.71073 \AA$ ) with a cryostat system equipped with a $\mathrm{N}_{2}$ generator (Japan Thermal Eng. Co., Ltd.). $\mathrm{C}_{79.19} \mathrm{H}_{90.83} \mathrm{I}_{6} \mathrm{~N}_{12} \mathrm{O}_{3.22} \mathrm{Zn}_{3}, M r=2219.87$, crystal dimensions $0.50 \times 0.30 \times 0.10 \mathrm{~mm}^{3}$, Orthorhombic, space group, $\mathrm{Pbca}, a=27.590(6)$, $b=13.673(3), c=45.606(9) \AA, V=17204(6) \AA^{3}, T=82 \mathrm{~K}, Z=8, \rho$ calcd $=1.714 \mathrm{~g} \mathrm{~cm}^{-3}$, 14779 unique reflections out of 21929 with $I>2 \sigma(I), 1256$ parameters, $1.72<\theta<29.13^{\circ}$, final $R$ factors $R_{1}=0.0442$ and $w R_{2}=0.1070$. 


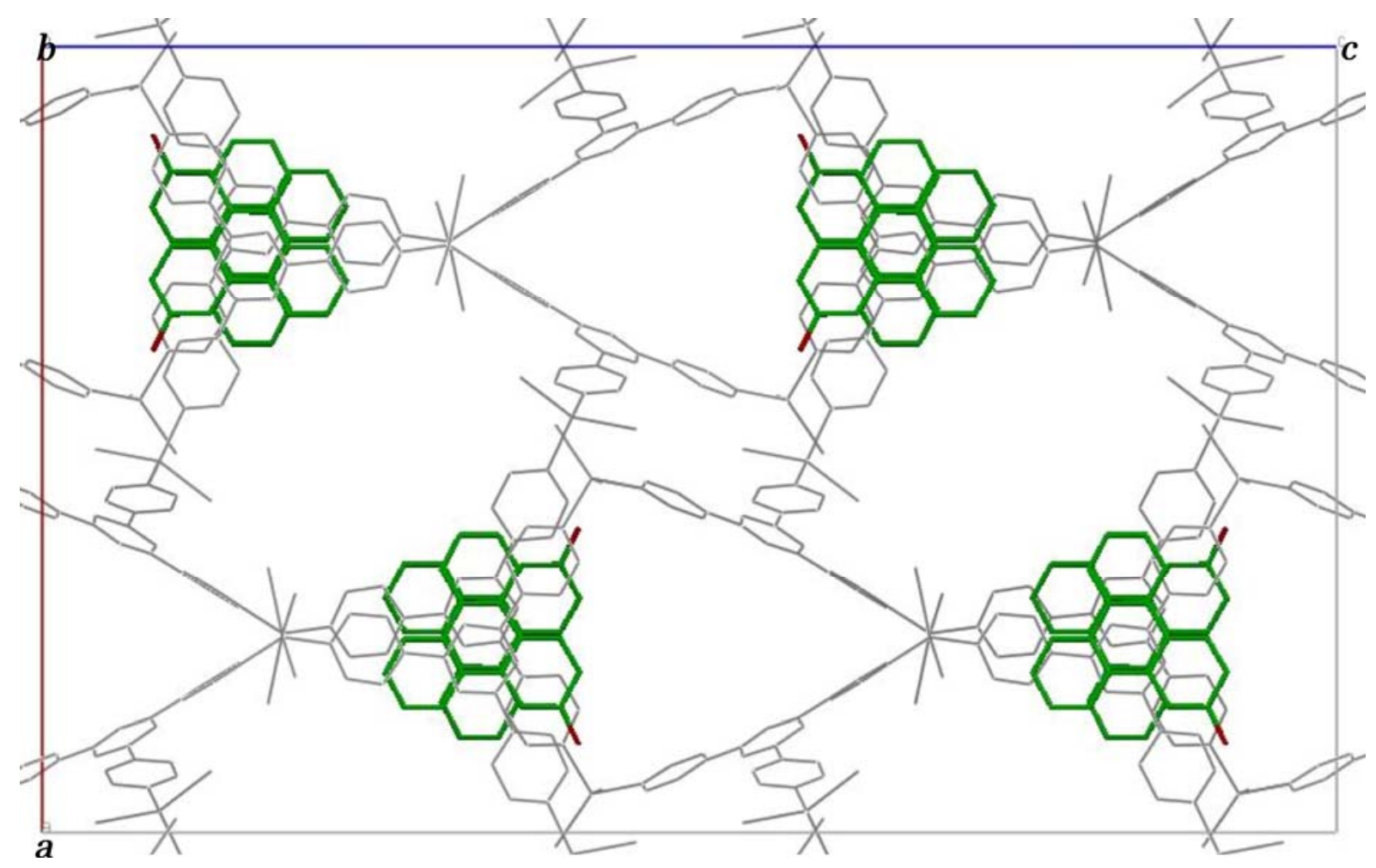

Figure S1. Crystal Structure of $\mathbf{3 b}$. A view along the $b$ axis. Guests in the pore are omitted for clarity. The porous network of $\left[\left(\mathrm{ZnI}_{2}\right)_{3}(\mathbf{1})_{2}\right]$ is shown in grey line. 2-hydroxytriphenylene molecules are shown in stick. Hydroxyl groups of $\mathbf{2} \mathbf{b}$ are assigned to the border of the pores $\mathrm{A}$ and pores B (62\%) and the pores A (38\%).

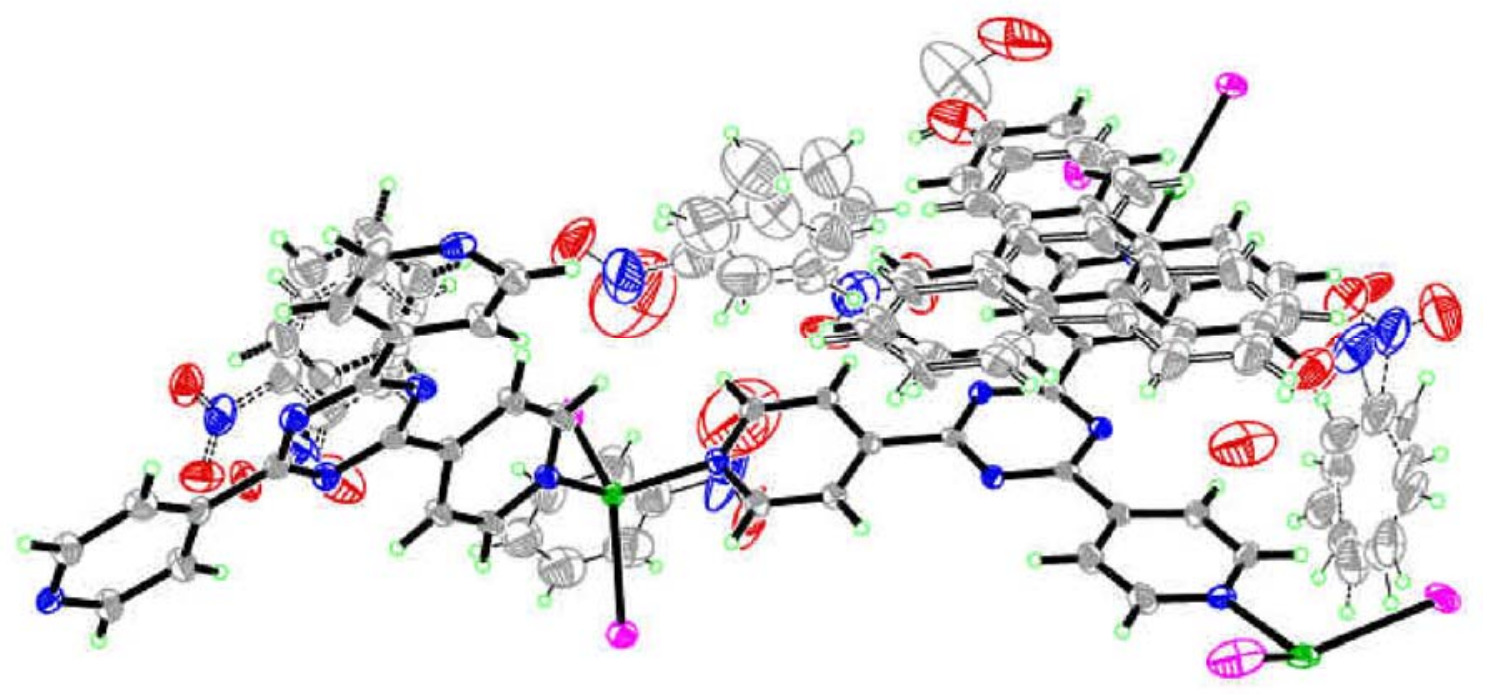

Figure S2. ORTEP drawing (30\% probability level) with the occupancy of $3 \mathbf{b}$. Several restraints were applied to severely disordered molecules on a basis of chemical symmetry of the molecules. 
(a)

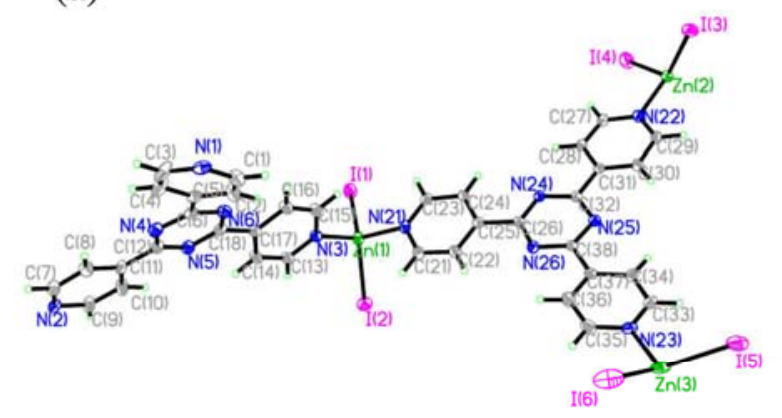

(b)

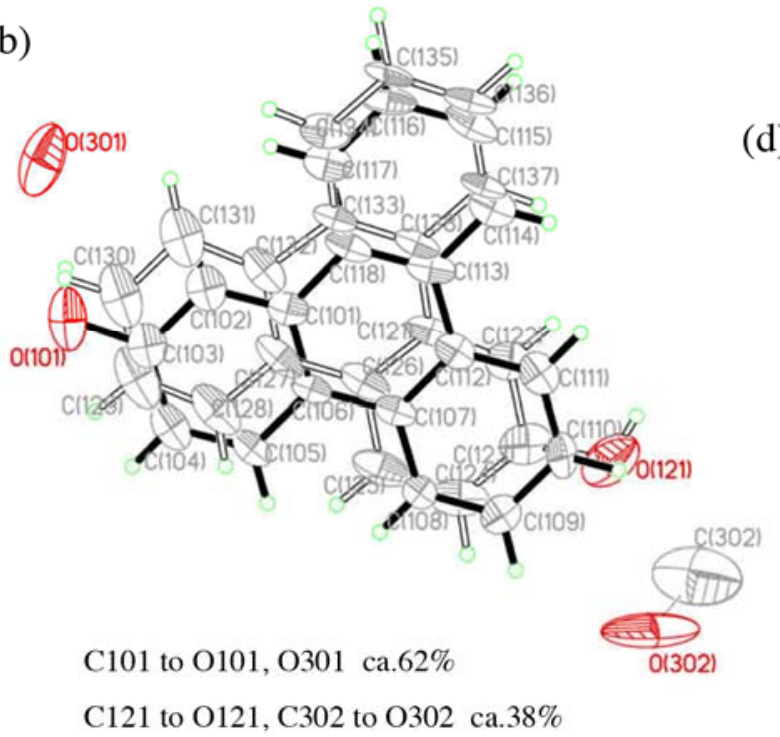

(c)

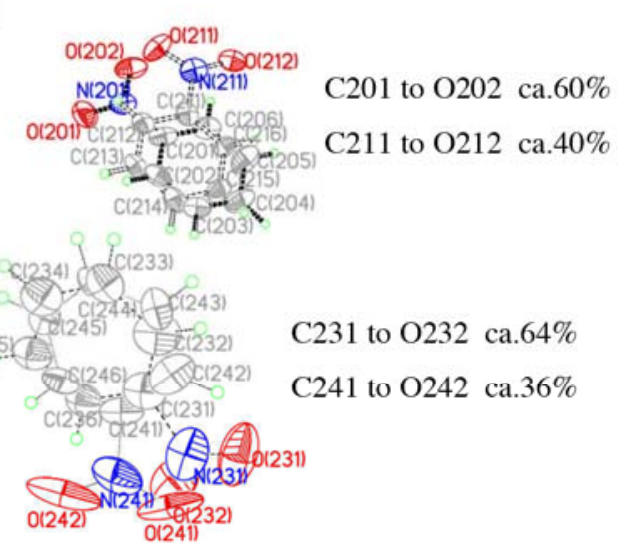

(d)

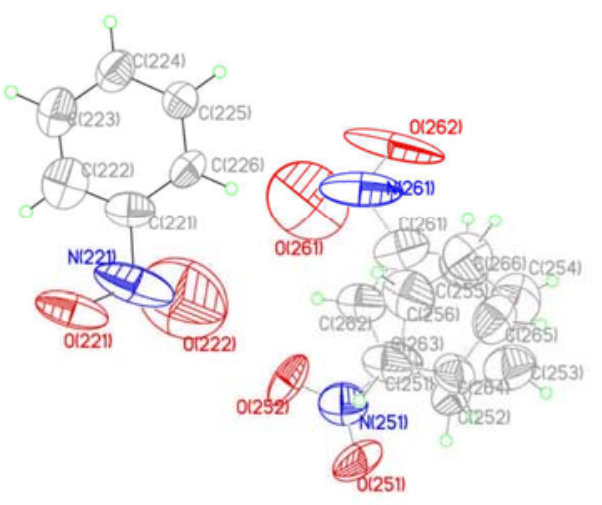

C251 to 0252 ca. $46 \%$

C261 to 0262 ca. $54 \%$

Figure S3. ORTEP drawing (30\% probability level) with the occupancy of $\mathbf{3 b}$ : (a) the framework, (b) intercalated 2-hydroxytriphenylene molecule and guest molecules bonded by hydrogen bonding (water and methanol molecules), (c) nitrobenzene molecules in pores $\mathbf{A}$, (d) nitrobenzene molecules in pores B. Several restraints were applied to severely disordered molecules on a basis of chemical symmetry of the molecules. 


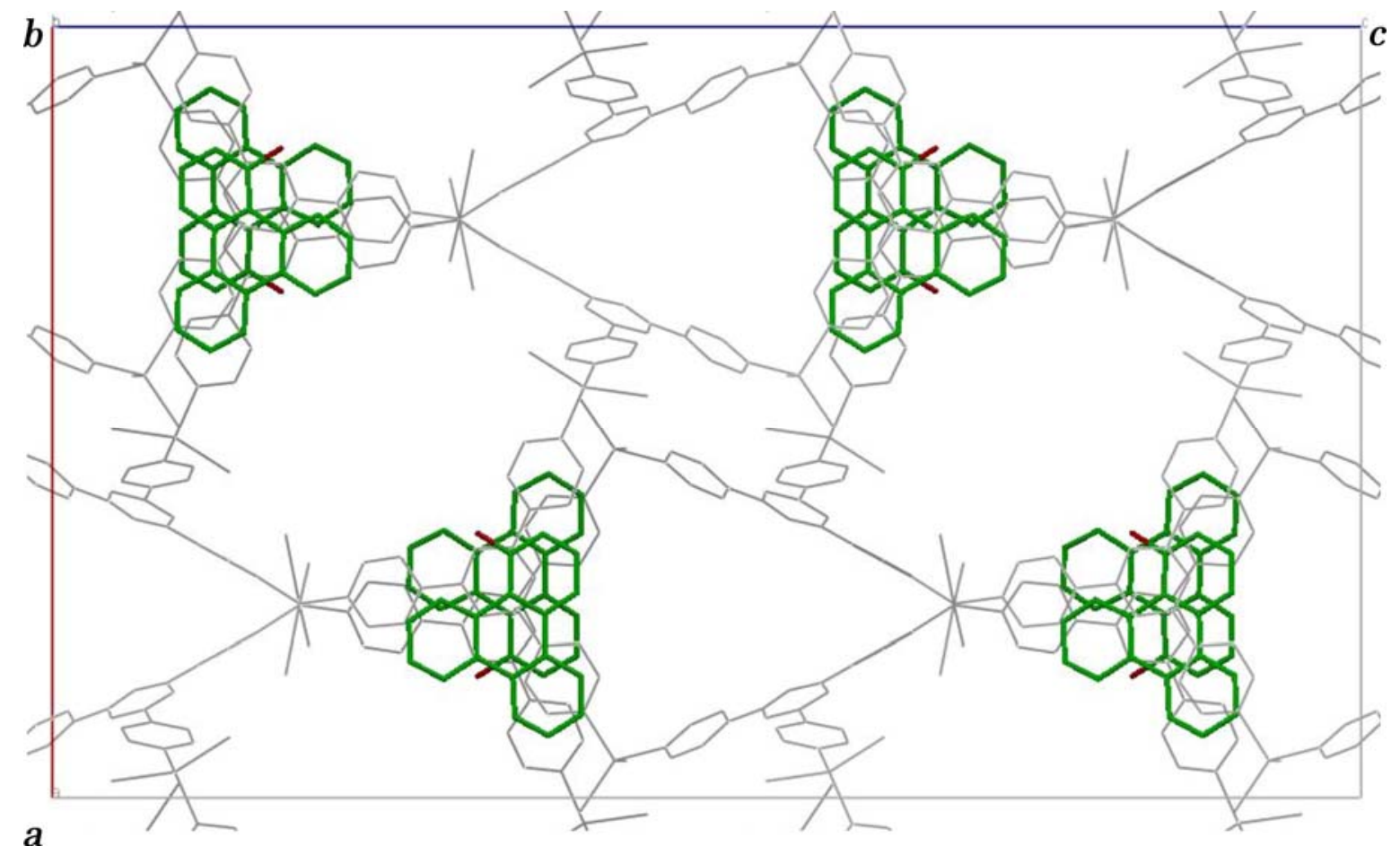

Figure S4. Crystal Structure of 3c. A view along the $b$ axis. Guests in the pore are omitted for clarity. The porous network of $\left[\left(\mathrm{ZnI}_{2}\right)_{3}(\mathbf{1})_{2}\right]$ is shown in grey line. 1-hydroxytriphenylene molecules are shown in stick. Hydroxyl groups of $\mathbf{2 c}$ are assigned to the pores A.

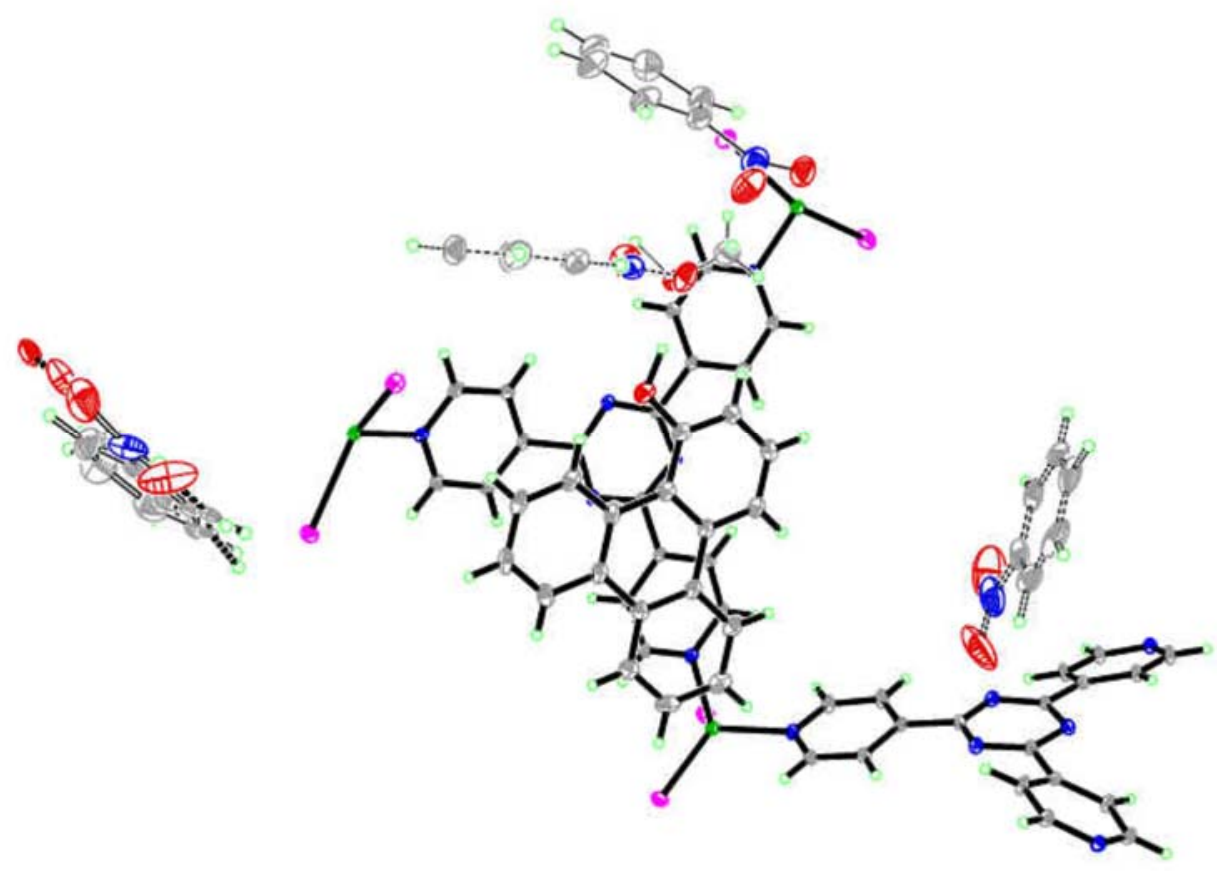

Figure S5. ORTEP drawing (30\% probability level) with the occupancy of 3c. 
(a)

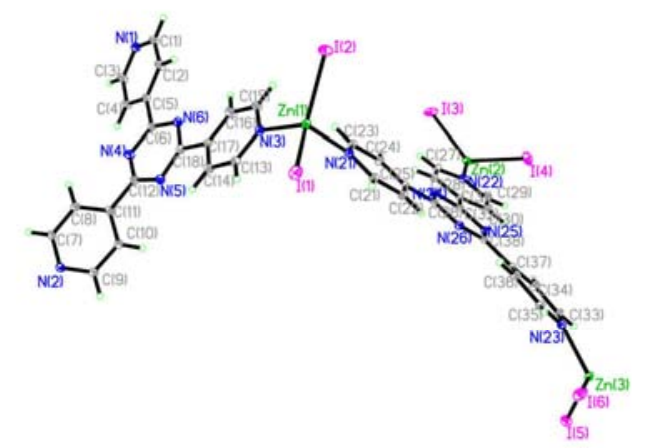

(b)

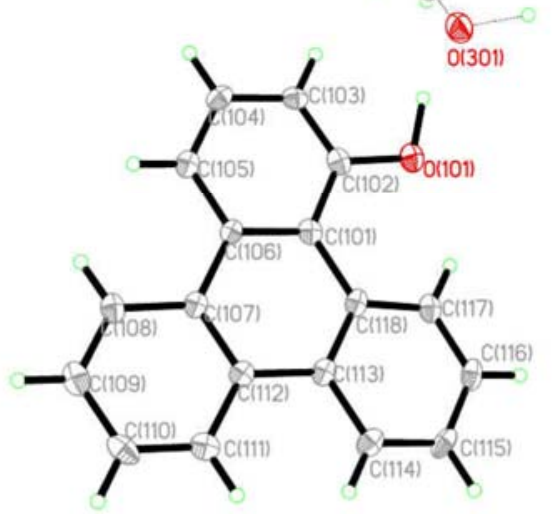

(c)

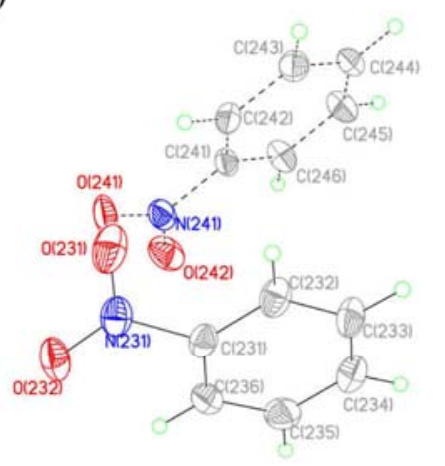

(d)

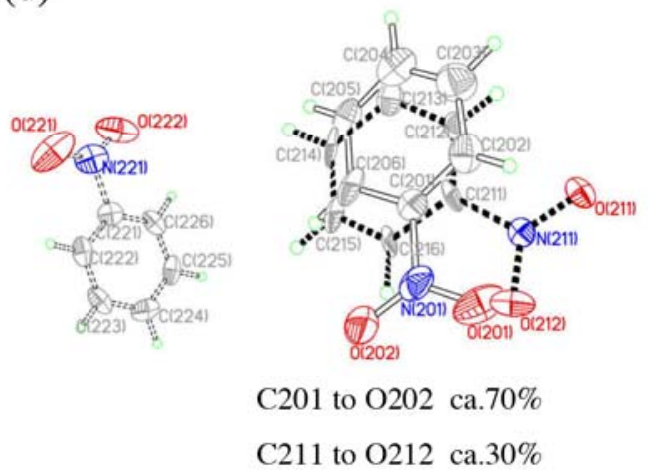

Figure S6. ORTEP drawing (30\% probability level) with the occupancy of 3c: (a) the framework, (b) intercalated 1-hydroxytriphenylene molecule and guest molecules bonded by hydrogen bonding (methanol molecules), (c) nitrobenzene molecules in pores $\mathbf{A}$, (d) nitrobenzene molecules in pores $\mathbf{B}$. 


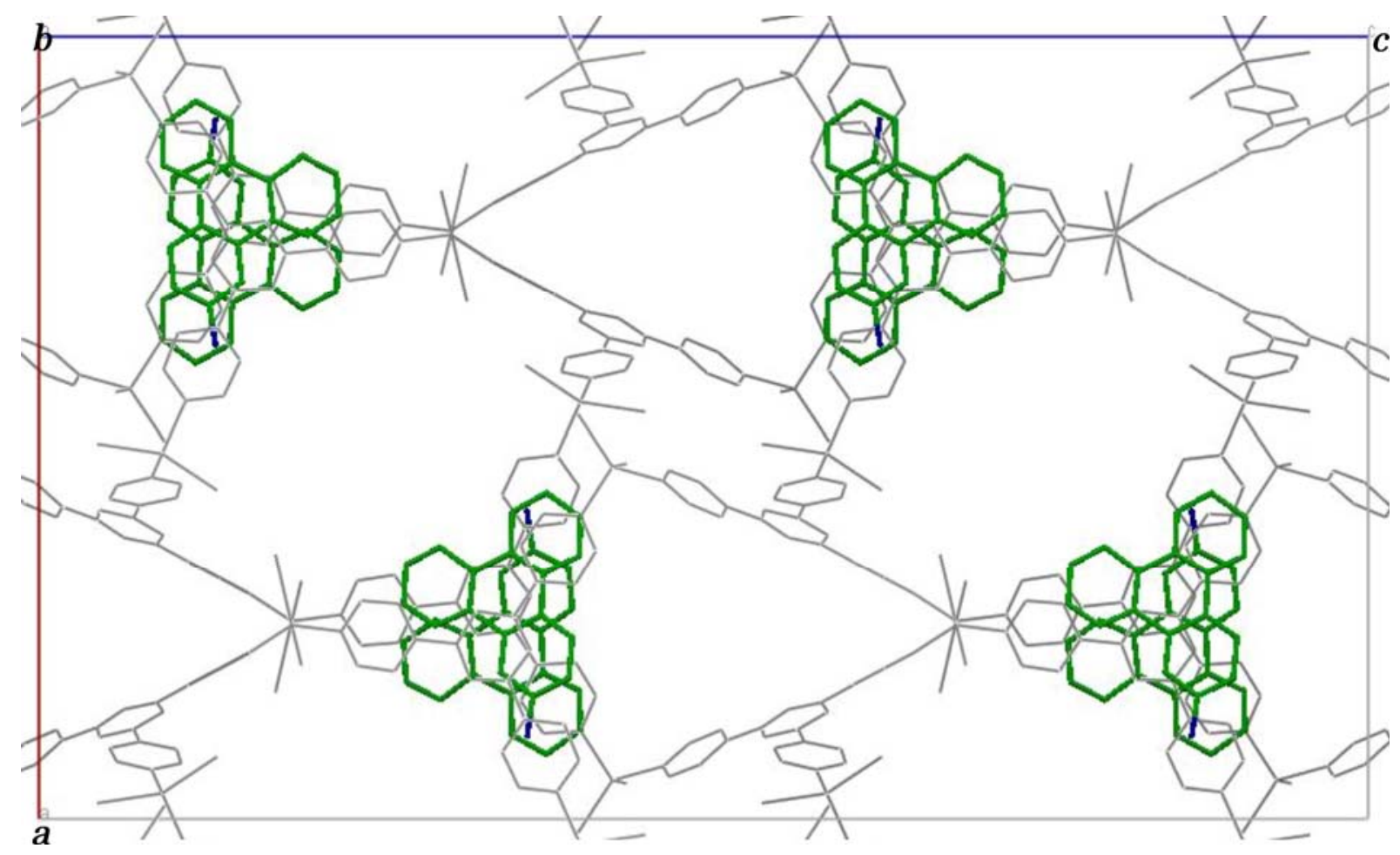

Figure S7. Crystal Structure of 3d. A view along the $b$ axis. Guests in the pore are omitted for clarity. The porous network of $\left[\left(\mathrm{ZnI}_{2}\right)_{3}(\mathbf{1})_{2}\right]$ is shown in grey line. 2-aminotriphenylene molecules are shown in stick. Amino groups of $\mathbf{2} \mathbf{d}$ are assigned to the pores A.

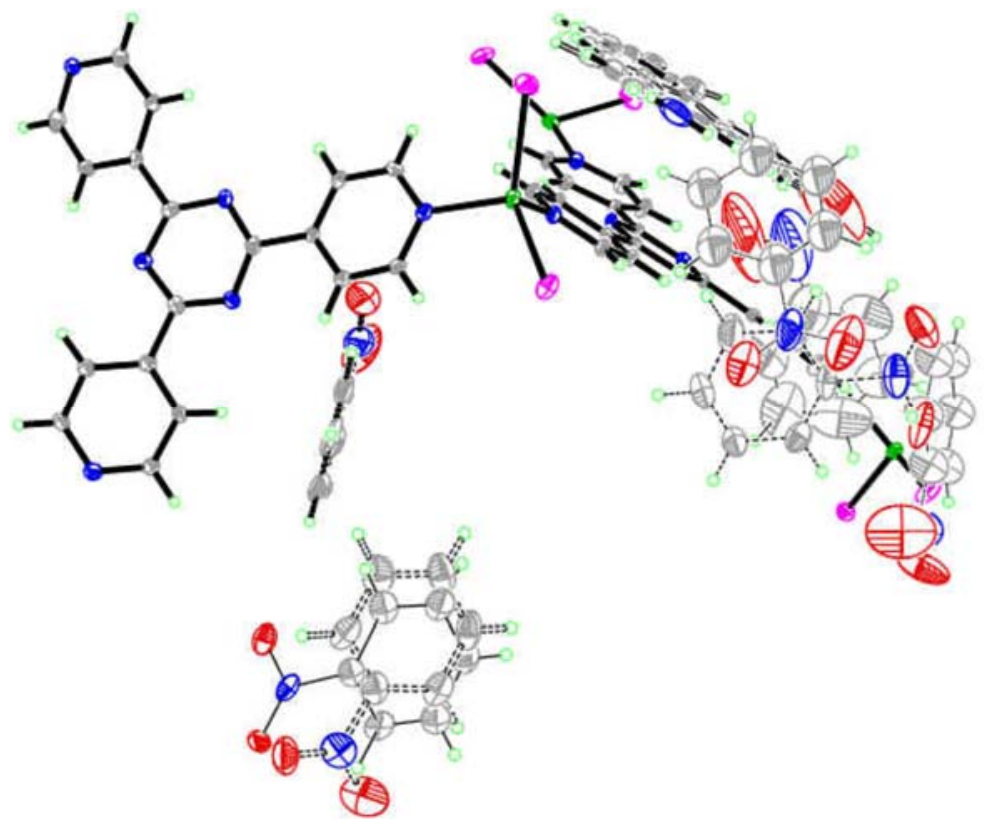

Figure S8. ORTEP drawing (30\% probability level) with the occupancy of 3d. Several restraints were applied to severely disordered molecules on a basis of chemical symmetry of the molecules. 
(a)

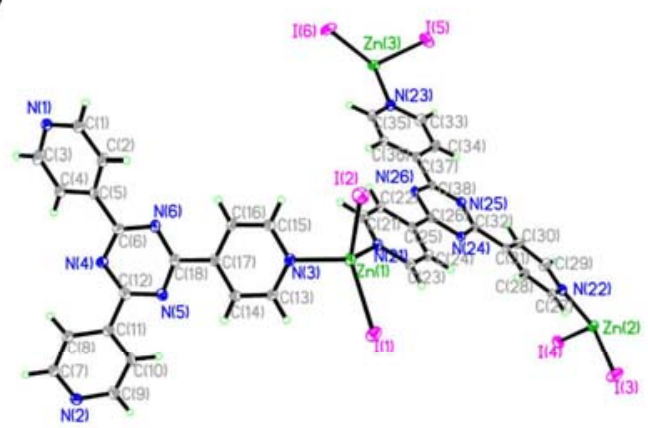

(b)

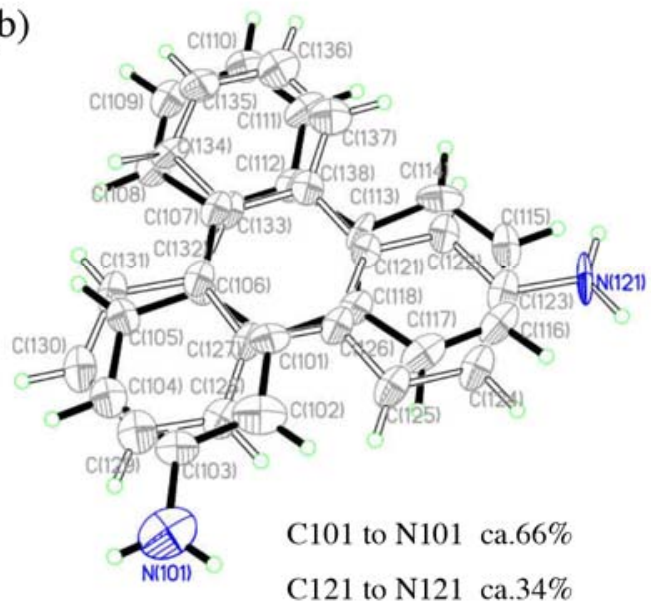

(c)

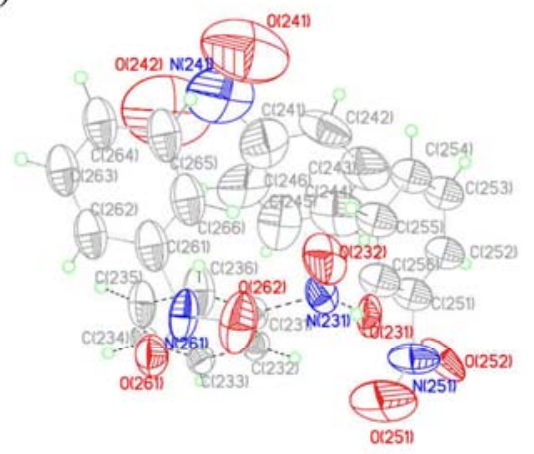

C231 to $\mathrm{O} 232$ ca. $72 \%$, $\mathrm{C} 241$ to $\mathrm{O} 242$ ca. $72 \%$

C251 to $\mathrm{O} 252$ ca. $28 \%$, $\mathrm{C} 261$ to $\mathrm{O} 262$ ca. $28 \%$

(d)

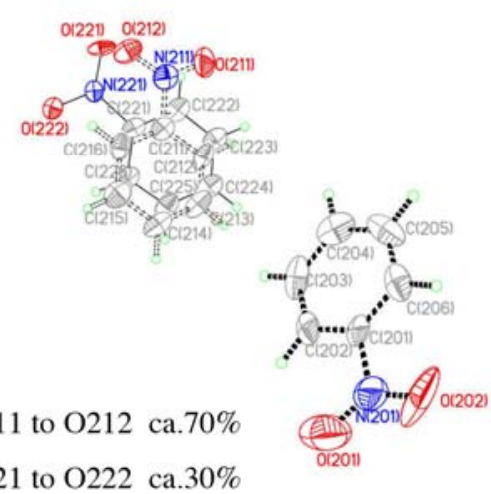

Figure S9. ORTEP drawing (30\% probability level) with the occupancy of 3d: (a) the framework, (b) intercalated 2-aminotriphenylene molecule, (c) nitrobenzene molecules in pores $\mathbf{A}$, (d) nitrobenzene molecules in pores B. Several restraints were applied to severely disordered molecules on a basis of chemical symmetry of the molecules. 


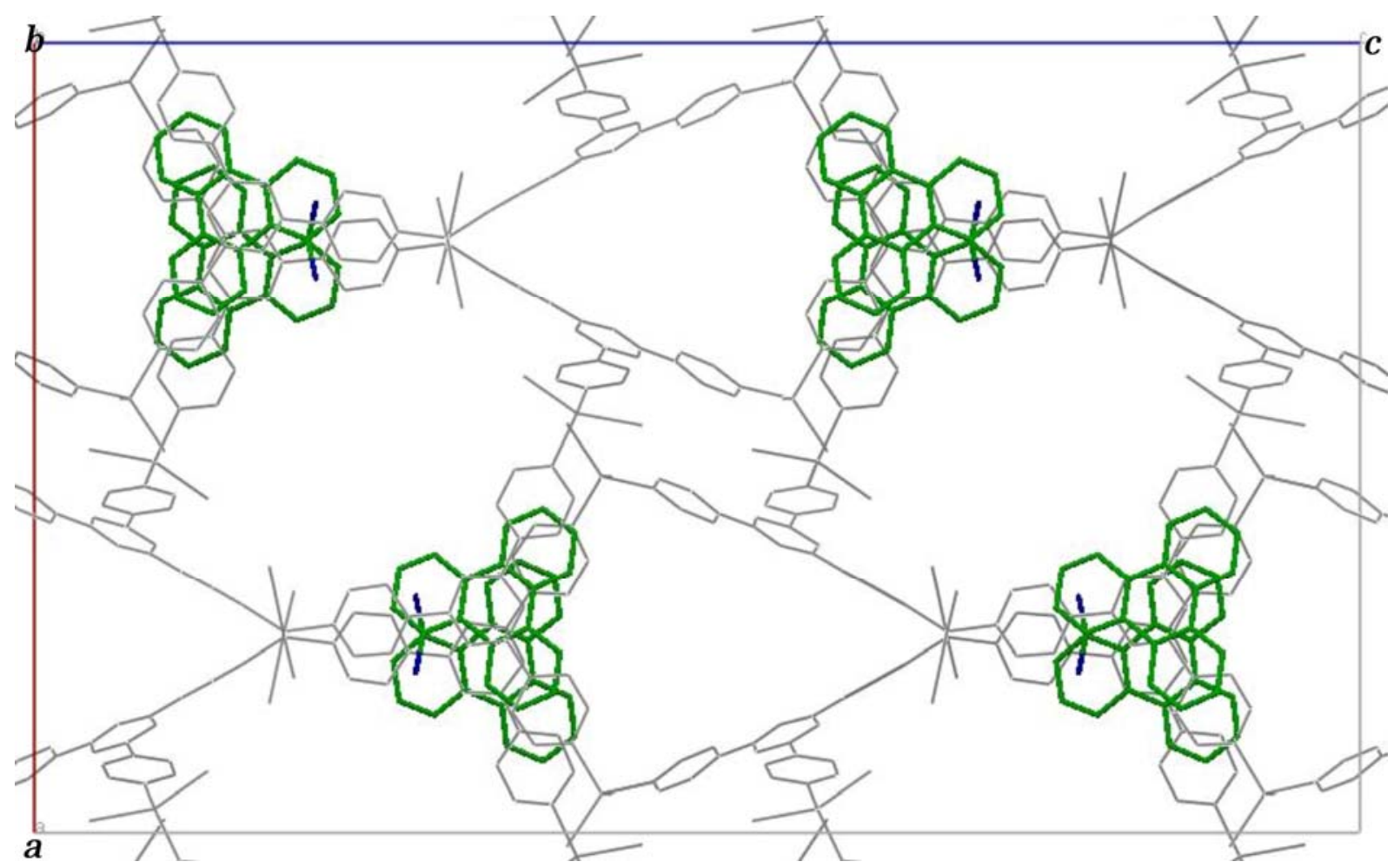

Figure S10. Crystal Structure of 3e. A view along the $b$ axis. Guests in the pore are omitted for clarity. The porous network of $\left[\left(\mathrm{ZnI}_{2}\right)_{3}(\mathbf{1})_{2}\right]$ is shown in grey line. 1-aminotriphenylene molecules are shown in stick. Amino groups of $2 \mathbf{e}$ are assigned to the pores A.

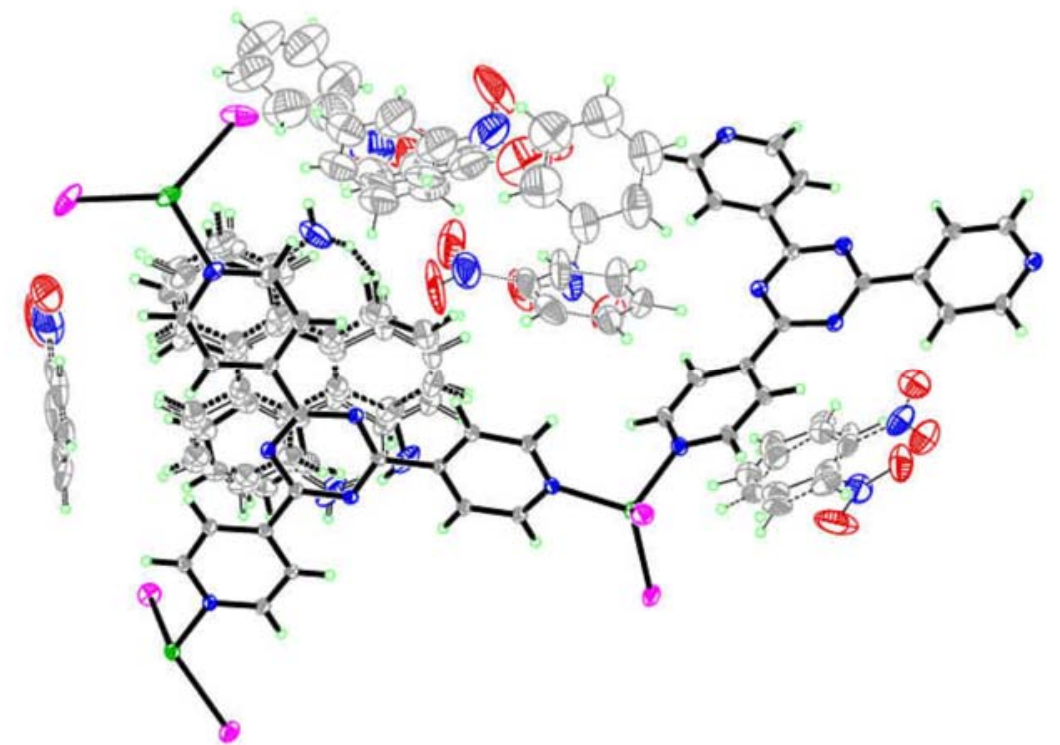

Figure S11. ORTEP drawing (30\% probability level) with the occupancy of 3e. Several restraints were applied to severely disordered molecules on a basis of chemical symmetry of the molecules. 
(a)

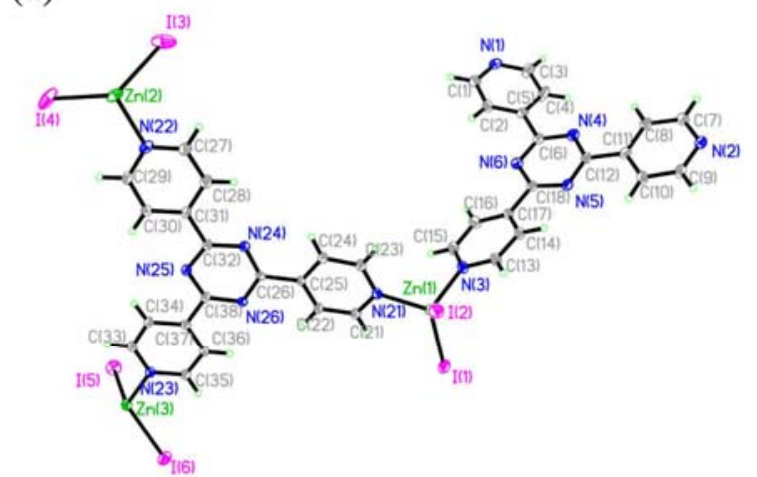

(b)

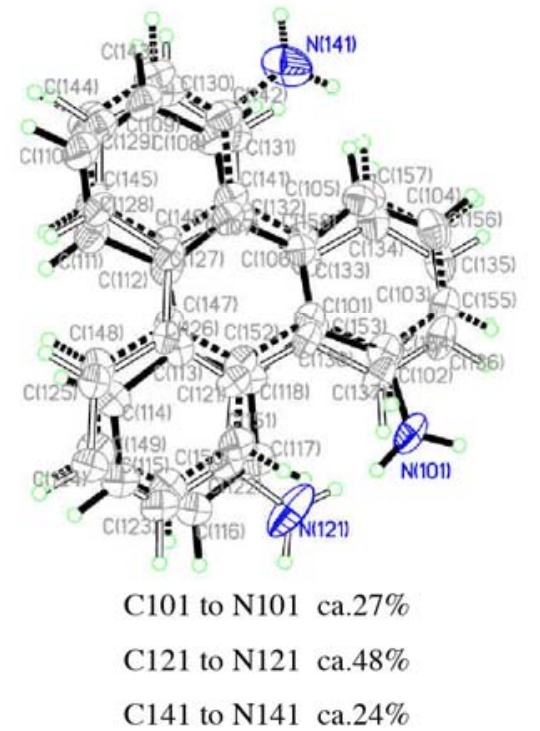

(c)

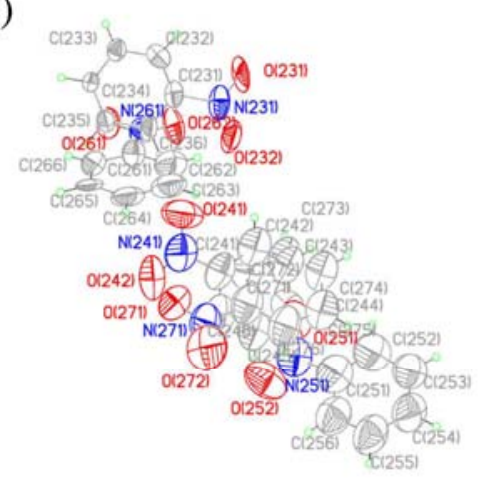

C231 to $\mathrm{O} 232$ ca. $72 \%, \mathrm{C} 241$ to $\mathrm{O} 242$ ca. $49 \%$

$\mathrm{C} 251$ to $\mathrm{O} 252$ ca. $28 \%$, $\mathrm{C} 261$ to $\mathrm{O} 262$ ca. $28 \%$

$\mathrm{C} 271$ to $\mathrm{O} 272$ ca. $26 \%$

(d)

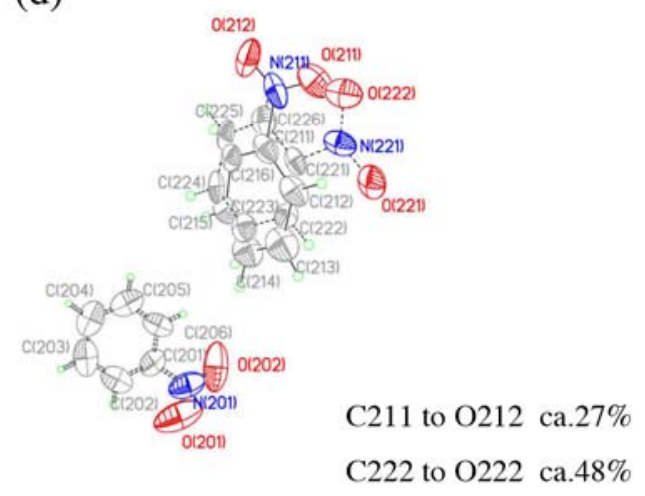

Figure S12. ORTEP drawing (30\% probability level) with the occupancy of 3e: (a) the framework, (b) intercalated 1-aminotriphenylene molecule, (c) nitrobenzene molecules in pores $\mathbf{A}$, (d) nitrobenzene molecules in pores B. Several restraints were applied to severely disordered molecules on a basis of chemical symmetry of the molecules. 


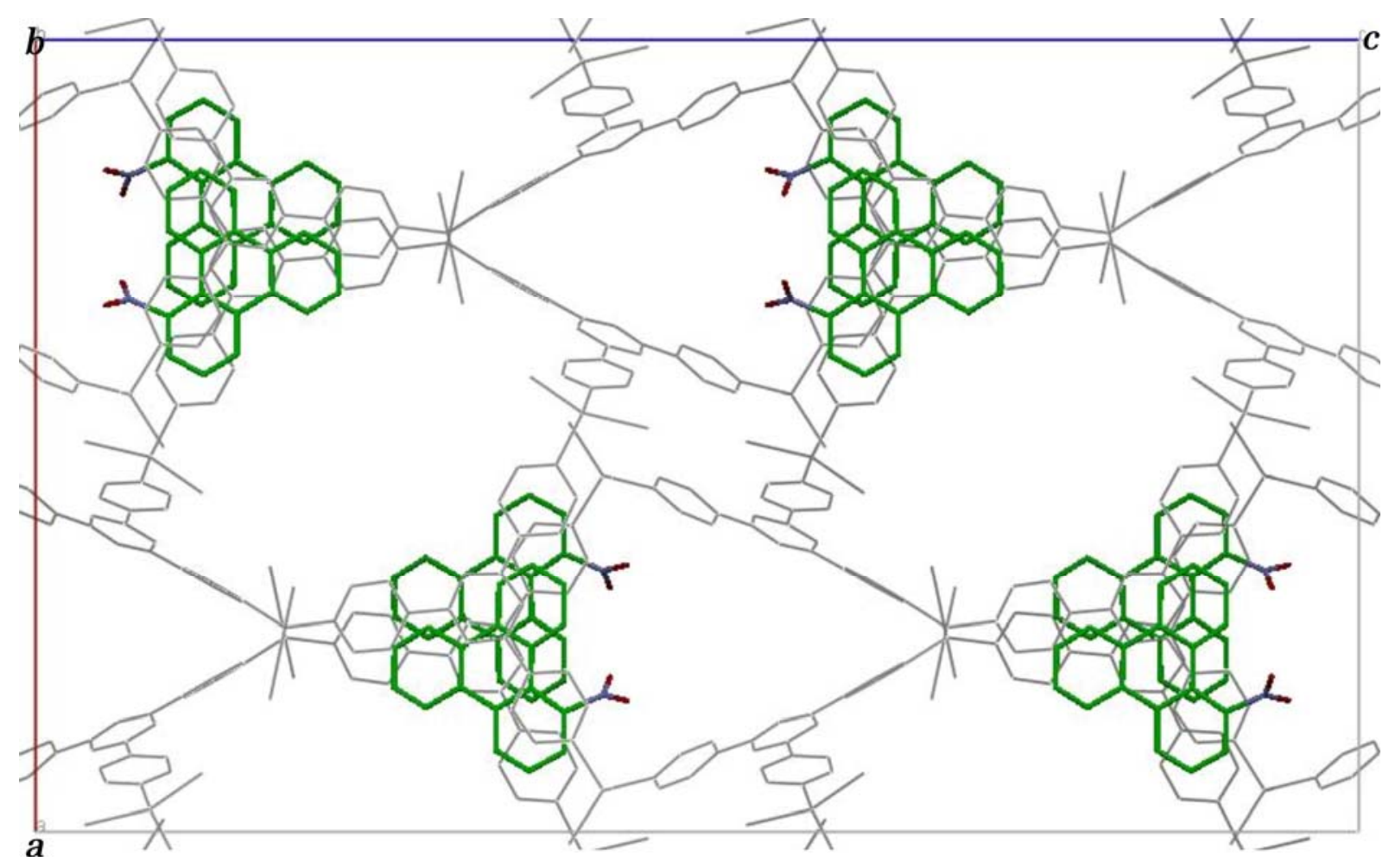

Figure S13. Crystal Structure of 3f. A view along the $b$ axis. Guests in the pore are omitted for clarity. The porous network of $\left[\left(\mathrm{ZnI}_{2}\right)_{3}(\mathbf{1})_{2}\right]$ is shown in grey line. 1-nitrotriphenylene molecules are shown in stick. Nitro groups of $\mathbf{2 f}$ are assigned to the pores B (77\%) and pores A (23\%).

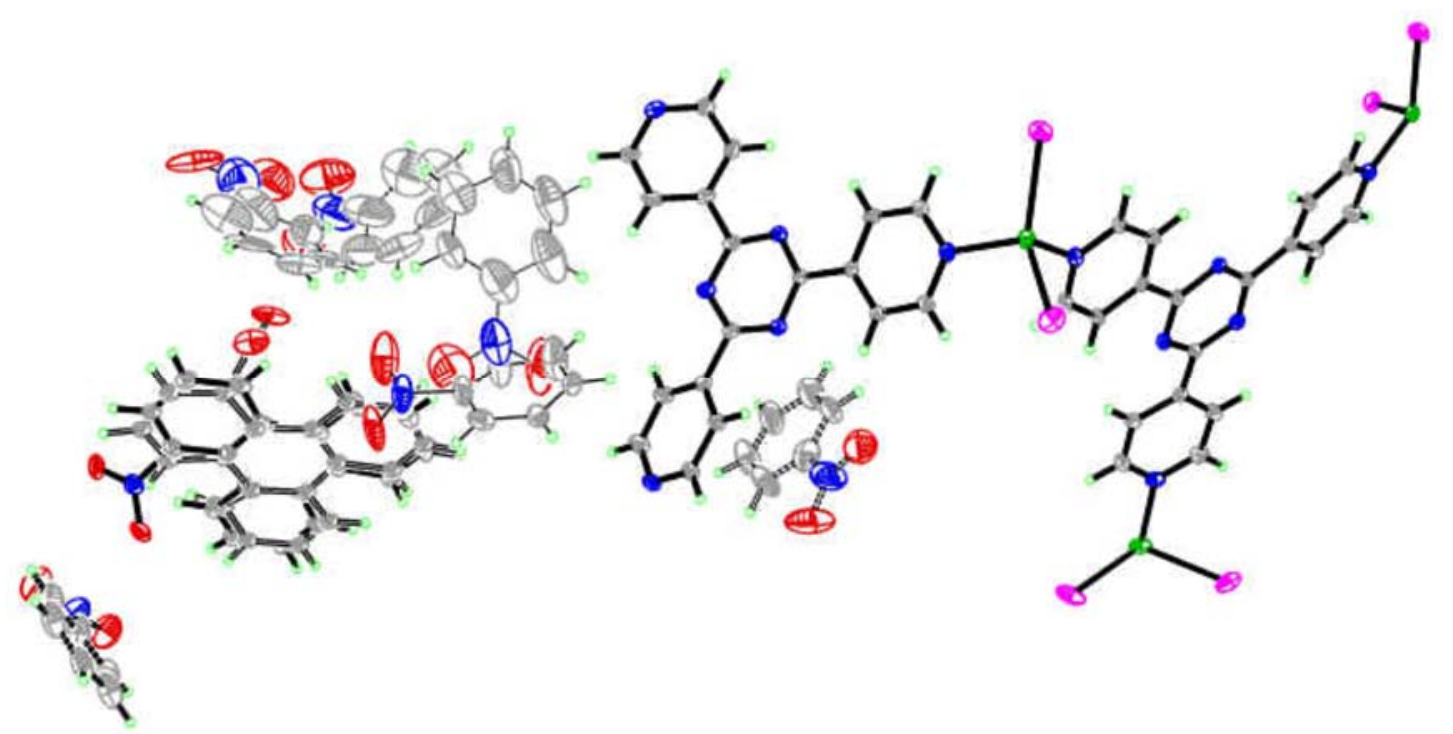

Figure S14. ORTEP drawing (30\% probability level) with the occupancy of 3f. Several restraints were applied to severely disordered molecules on a basis of chemical symmetry of the molecules. 
(a)

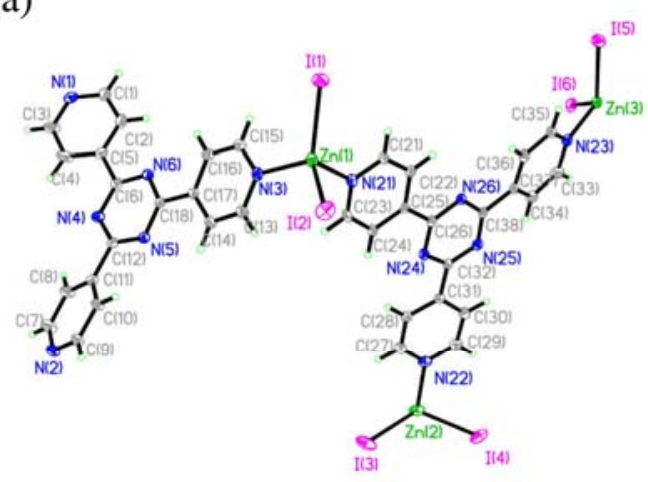

(b)

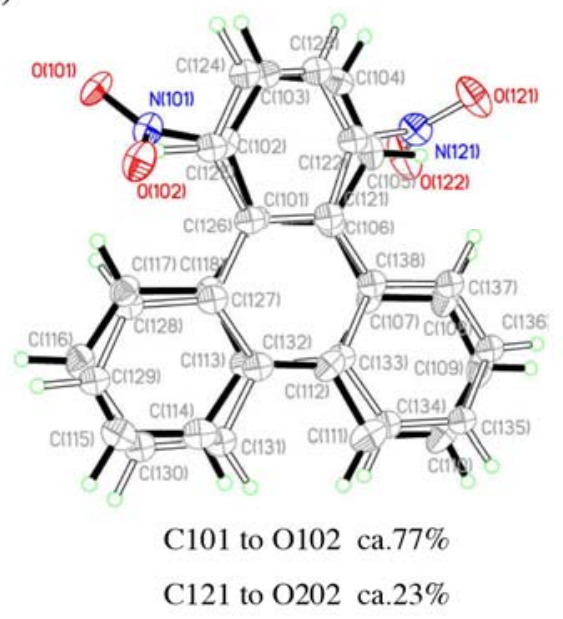

(c)

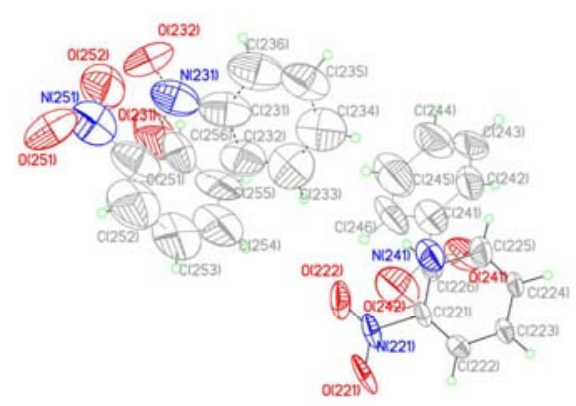

$\mathrm{C} 231$ to $\mathrm{O} 232 \mathrm{ca} .67 \%, \mathrm{C} 241$ to $\mathrm{O} 242$ ca.67\%

C251 to $\mathrm{O} 252$ ca.33\%, C261 to $\mathrm{O} 262$ ca.33\%

(d)

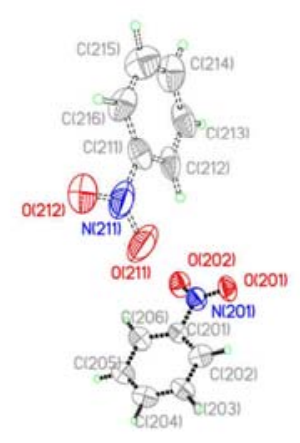

Figure S15. ORTEP drawing (30\% probability level) with the occupancy of 3f: (a) the framework, (b) intercalated 1-nitrotriphenylene molecule, (c) nitrobenzene molecules in pores $\mathbf{A}$, (d) nitrobenzene molecules in pores $\mathbf{B}$. Several restraints were applied to severely disordered molecules on a basis of chemical symmetry of the molecules. 
(a)

(b)

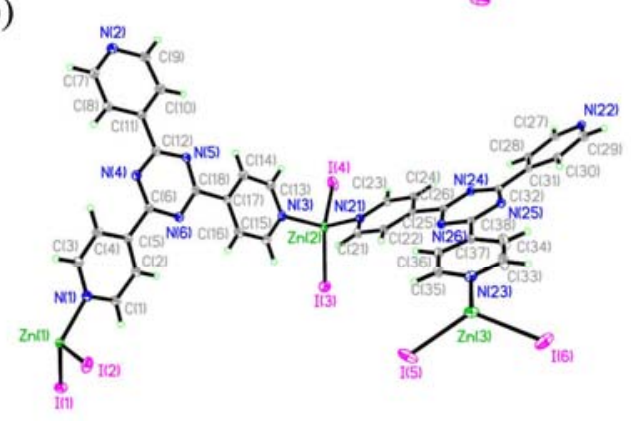

(c)

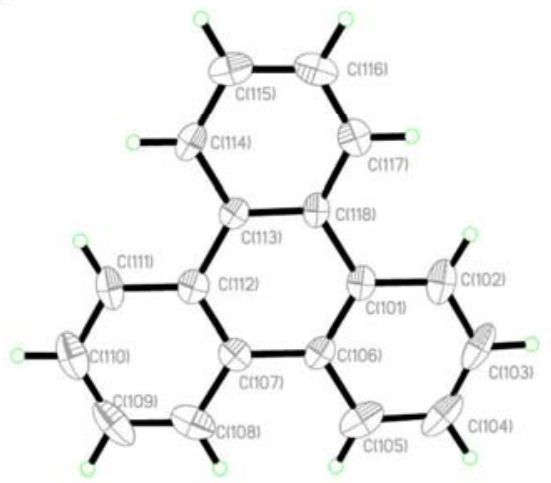

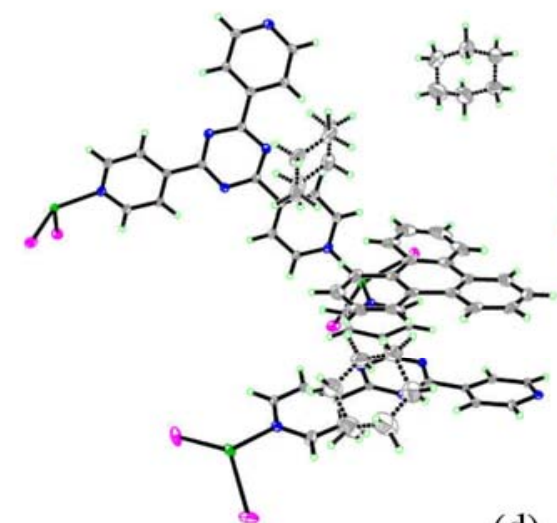

(d)

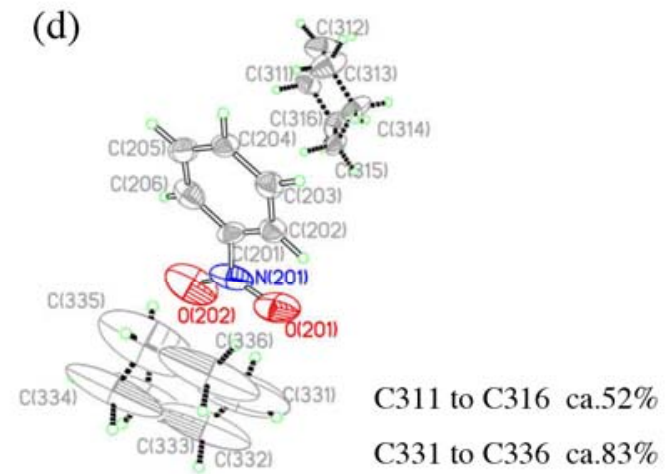

(e)
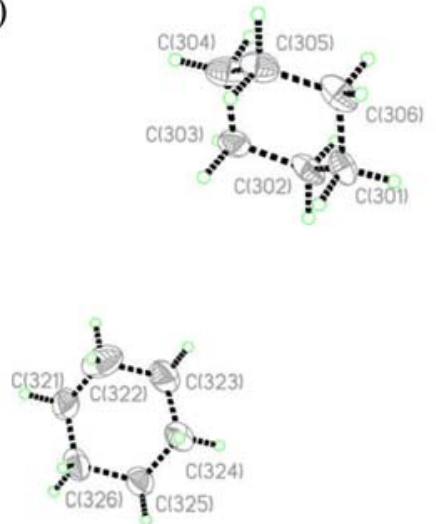

Figure S16. ORTEP drawing (30\% probability level) with the occupancy of 4a: (a) all components, (b) the framework, (c) intercalated triphenylene molecule, (d) nitrobenzene and cyclohexane molecules in pores A, (e) cyclohexane molecules in pores B. Several restraints were applied to severely disordered molecules on a basis of chemical symmetry of the molecules. 
(a)

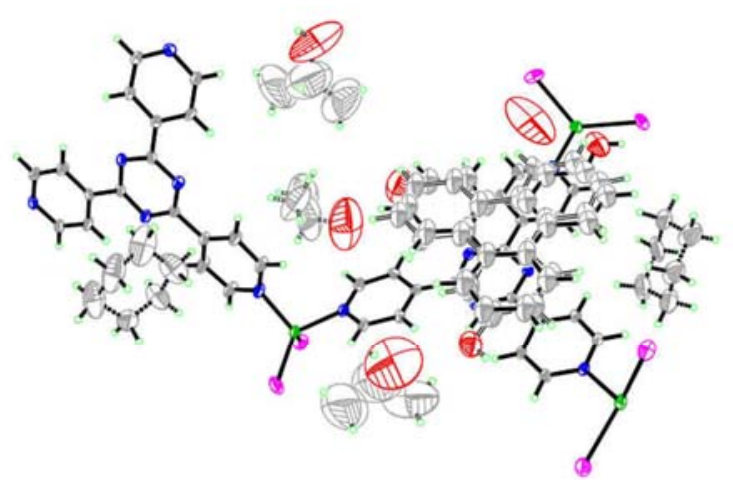

(b)

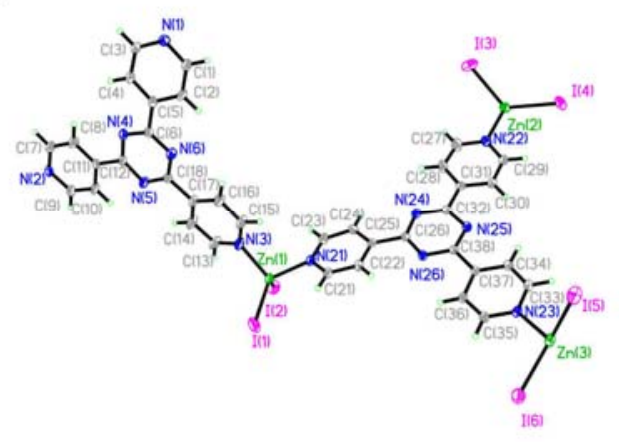

(c)

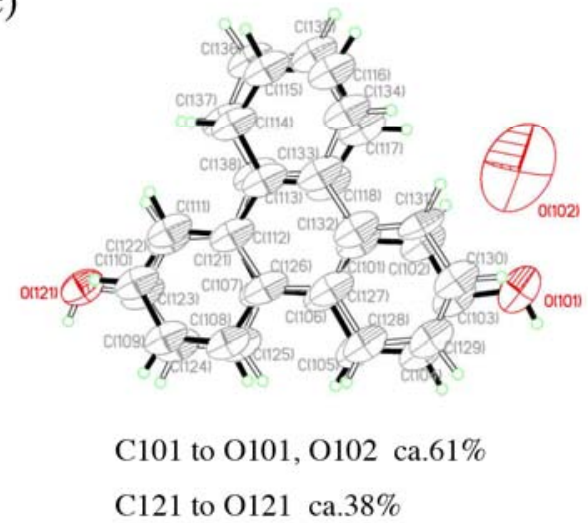

(d)

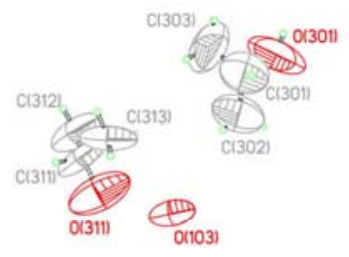

0103 са. $50 \%$

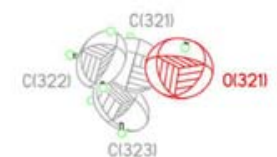

(e)
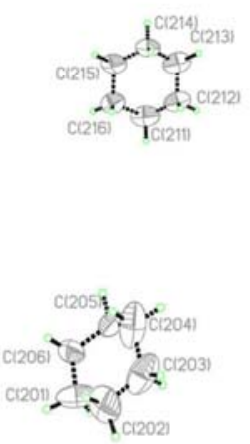

Figure S17. ORTEP drawing (30\% probability level) with the occupancy of $\mathbf{4 b}$ : (a) all components, (b) the framework, (c) intercalated 2-hydroxytriphenylene molecule and guest molecules bonded by hydrogen bonding (water molecules), (d) propane-2-ol and water molecules in pores A, (e) cyclohexane molecules in pores $\mathbf{B}$. Several restraints were applied to severely disordered molecules on a basis of chemical symmetry of the molecules. 
(a)

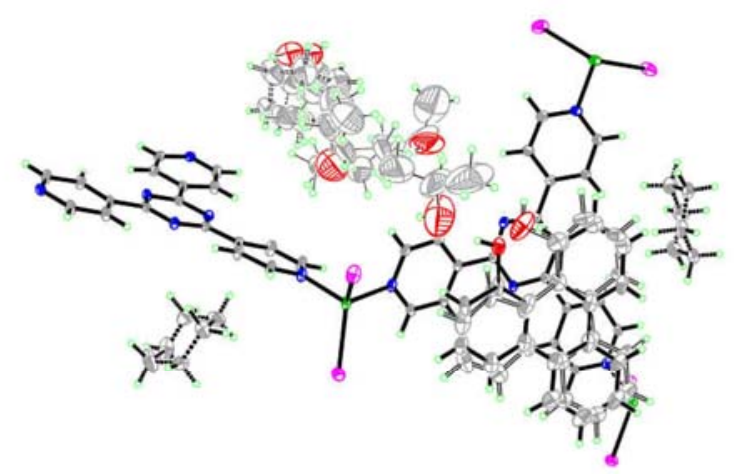

(b)

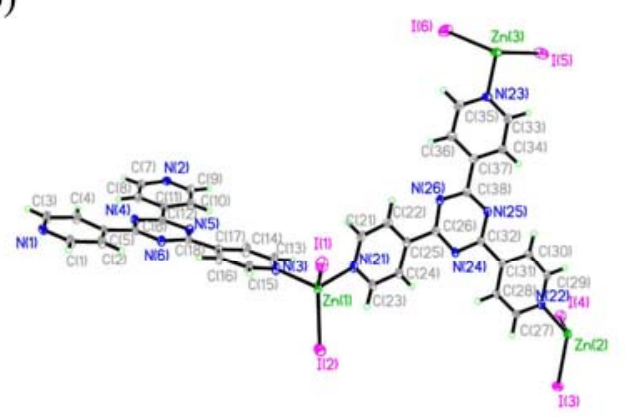

(c)

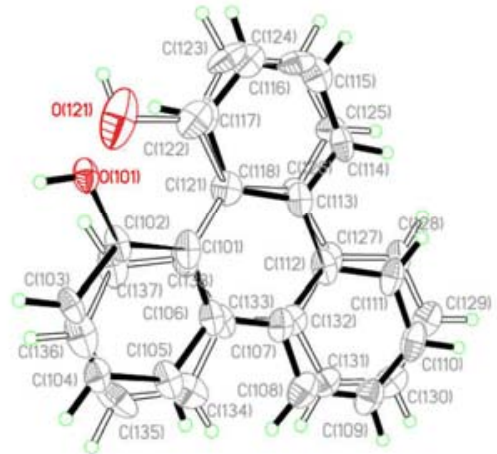

C101 to 0101 ca. $48 \%$

C121 to 0121 ca. $52 \%$ (d)

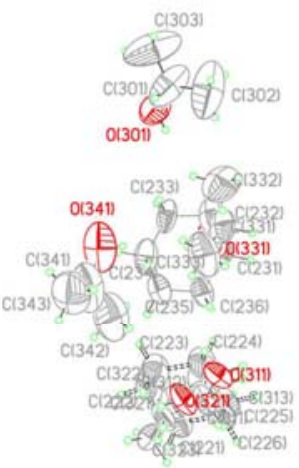

C221 to C226 ca.48\%, C231 to C236 ca.60\%

C311 to 0311 ca. $24 \%$, C321 to 0321 ca. $26 \%$

C331 to $\mathrm{O} 331$ ca. $40 \%$, C341 to $\mathrm{O} 341$ ca. $40 \%$

(e)<smiles>CC1C(C)C(C)C(C)C(C)C1C</smiles>

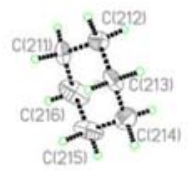

Figure S18. ORTEP drawing (30\% probability level) with the occupancy of 4c: (a) all components, (b) the framework, (c) intercalated 1-hydroxytriphenylene molecule, (d) propane-2-ol and cyclohexane molecules in pores A, (e) cyclohexane molecules in pores B. Several restraints were applied to severely disordered molecules on a basis of chemical symmetry of the molecules. 
(a)

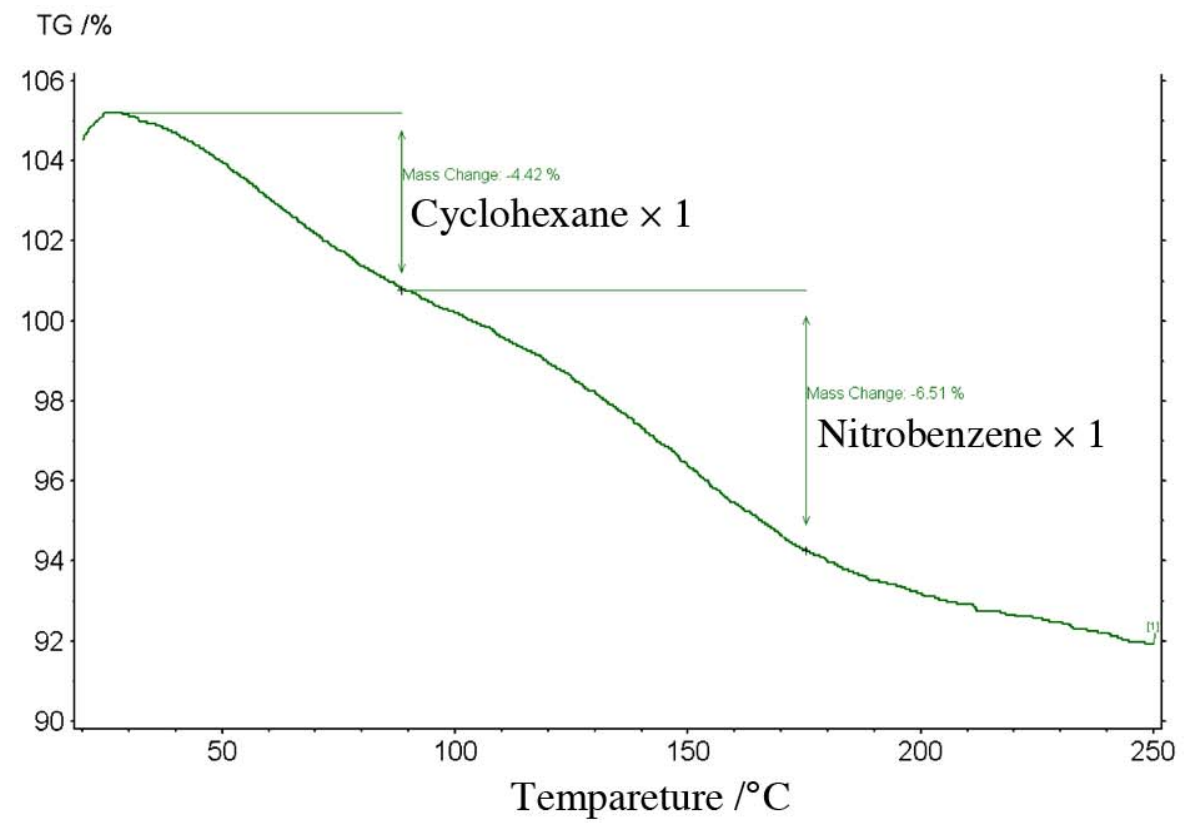

(b)

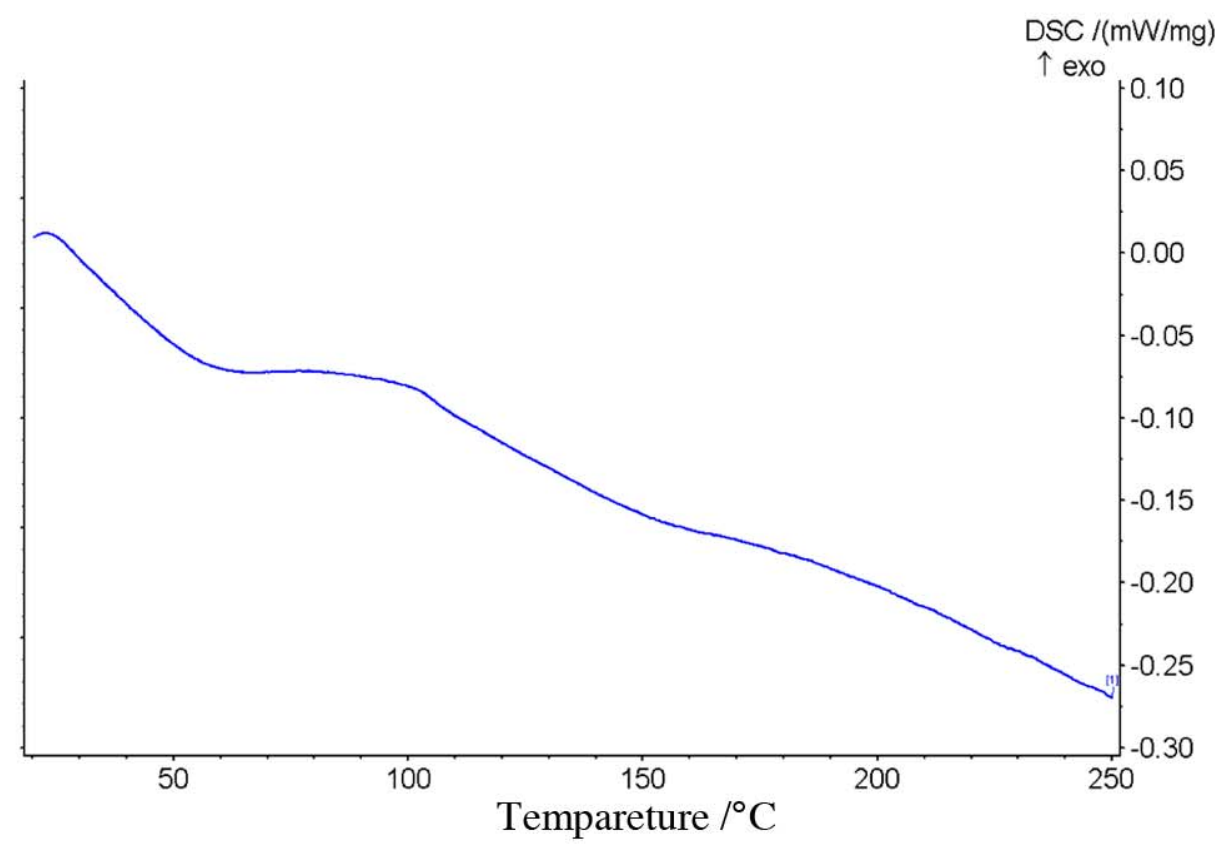

Figure S19. (a) TGA curve for 4a. (b) DSC curve for $4 a$. 
(a)

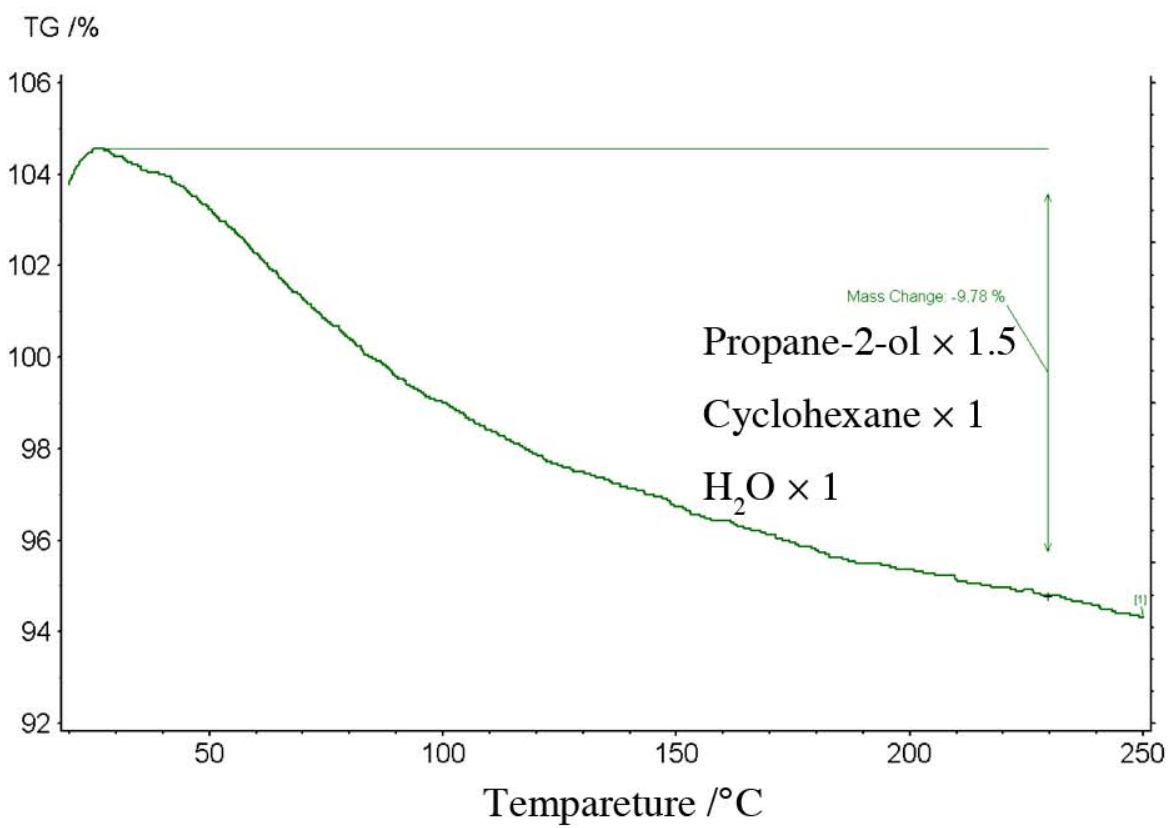

(b)

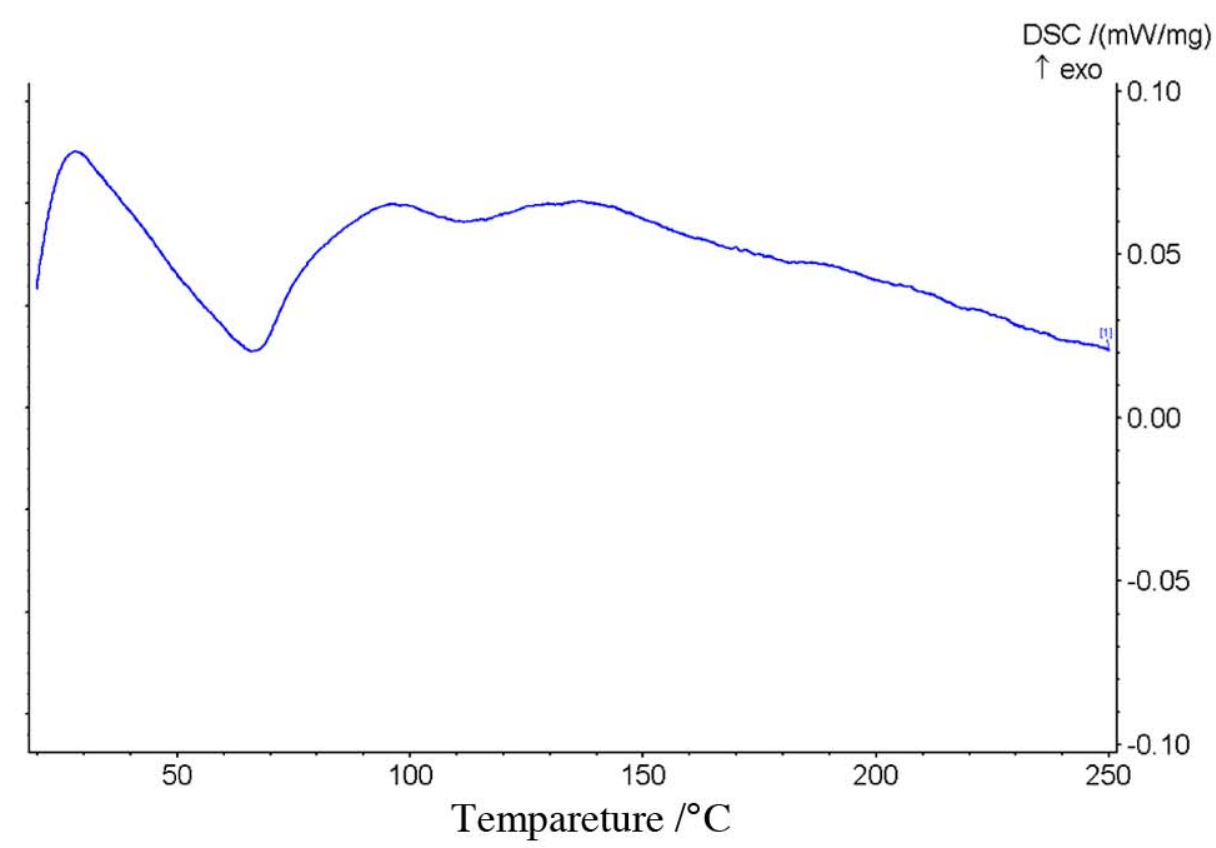

Figure S20. (a) TGA curve for $\mathbf{4 b}$. (b) DSC curve for $\mathbf{4 b}$. 
(a)

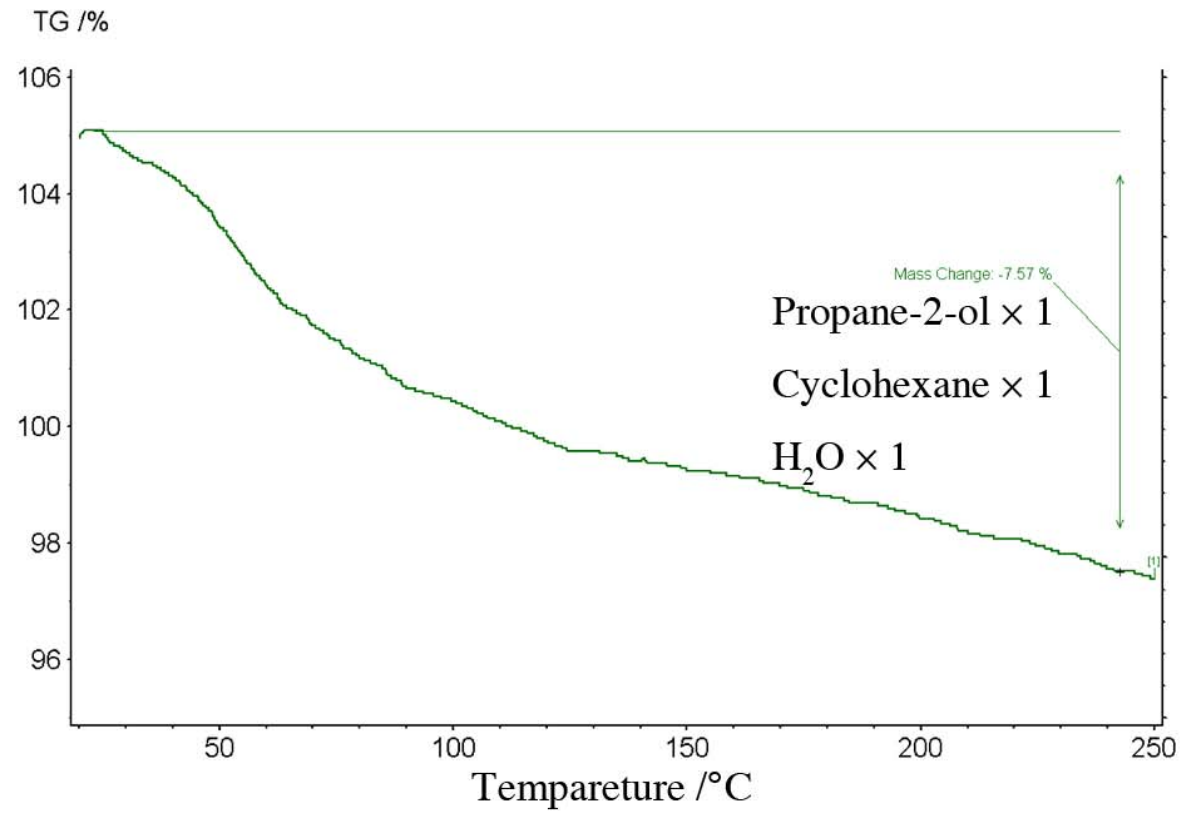

(b)

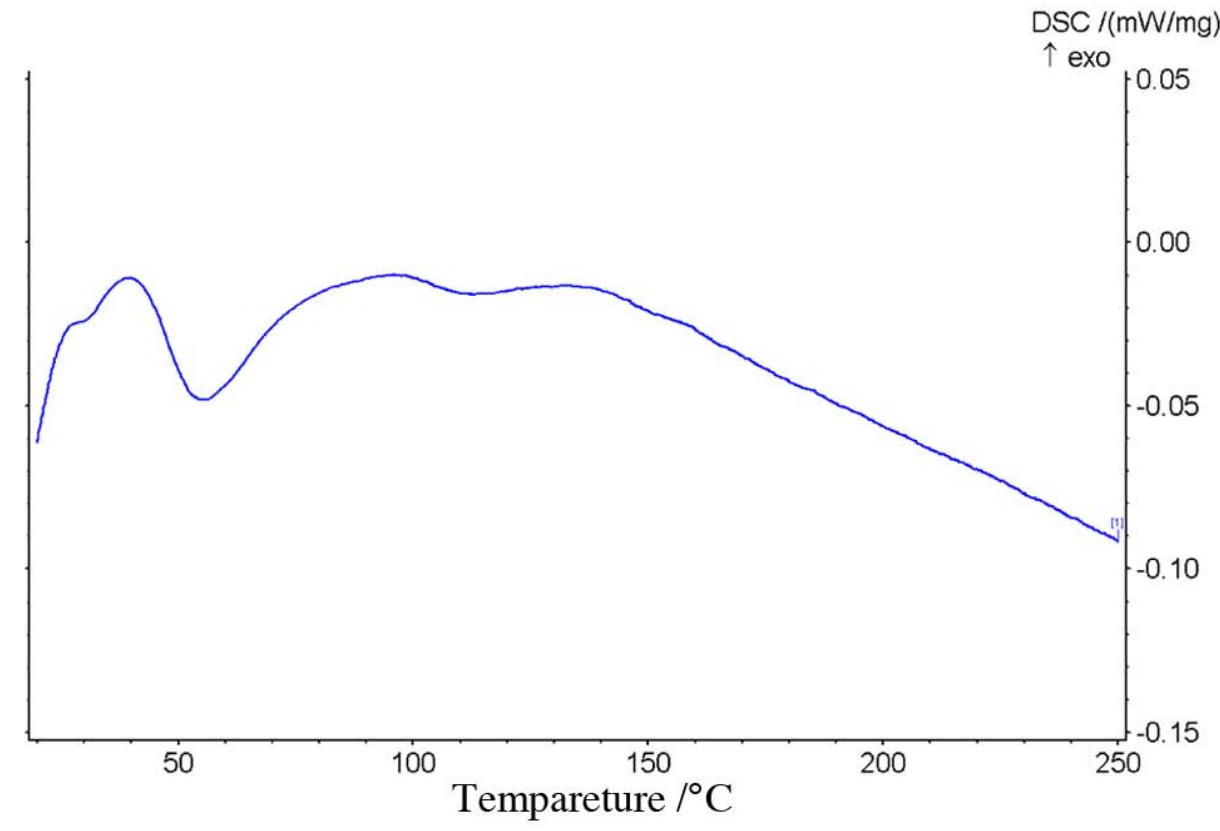

Figure S21. (a) TGA curve for $\mathbf{4 c}$. (b) DSC curve for $\mathbf{4 c}$. 